\title{
Tangential Networks of Precocious Neurons and Early Axonal Outgrowth in the Embryonic Human Forebrain
}

\author{
Irina Bystron, ${ }^{1,3}$ Zoltán Molnár, ${ }^{2}$ Vladimir Otellin, ${ }^{3}$ and Colin Blakemore ${ }^{1}$ \\ ${ }^{1}$ University Laboratory of Physiology, University of Oxford, Oxford OX1 3PT, United Kingdom, ${ }^{2}$ Department of Human Anatomy and Genetics, University \\ of Oxford, Oxford OX1 3QX, United Kingdom, and '3Department of Morphology, Institute of Experimental Medicine, St. Petersburg 197376, Russia
}

\begin{abstract}
We used a combination of immunohistochemistry and carbocyanine dye tracing to study neurons and their processes in the human embryonic forebrain, 4-7 weeks after conception, before the onset of synaptogenesis. We discovered a widespread network of precocious MAP2 (microtubule-associated protein 2)-immunoreactive cells, with long, nonaxonal processes, before the appearance of the cortical plate and the establishment of thalamocortical connectivity. Dye tracing revealed that the processes of these precocious cells form tangential links between intermediate zones of the thalamus, ganglionic eminence, hypothalamus, and cortical preplate. The spatiotemporal distribution and morphology of the precocious neurons in the cortical preplate suggest that they are generated outside the cerebral wall rather than in the local ventricular zone. The first thalamocortical axons and axons of preplate cells extend across diencephalotelencephalic and striatocortical boundaries before the arrival of the first cortical plate neurons. Precocious cells may provide initial communication between subdivisions of the embryonic brain as well as guidance cues for navigation of growing axons and/or transverse neuronal migration.
\end{abstract}

Key words: human forebrain development; pioneer neurons; thalamocortical and corticofugal projections; preplate; MAP2; GAP43

\section{Introduction}

Species-specific differences in the connectivity of the forebrain may be established at very early stages of prenatal development (Sidman and Rakic, 1973, 1982). In the human embryo, it is not clear what events precede the first axonal projections, but socalled "pioneer" neurons might play an important role. Such early maturing, often transient cells and their processes, which were first observed in invertebrates (Bate, 1976), are associated with growing axons in various regions of the nervous system in several mammalian species (Knyihár et al., 1978; Goodman and Shatz, 1993; Macdonald et al., 1994; Deng and Elberger, 2003). In rodents, thalamocortical fibers pass among cells of the thalamic reticular nucleus and the so-called perireticular nucleus (PRN), as they leave the diencephalon and grow toward and through the internal capsule (IC) (Mitrofanis and Baker, 1993; Métin and Godement, 1996). Although equivalent transient neuronal groups have been described in the human fetal forebrain (Letinic and Kostovic, 1996; Ulfig et al., 1998, 2000), little is known about their early development or their role in the establishment of thalamocortical connectivity.

The subplate zone, first recognized in the fetal human telencephalon (Kostovic and Rakic, 1980), is another mostly transient

Received Nov. 22, 2004; revised Jan. 24, 2005; accepted Jan. 24, 2005.

This work was supported by grants to C.B. (Medical Research Council Grant G9706008), to Z.M. (Medical Research Council Grant G0300200), and to V.0. (Leading Scientific Schools in Russia Grant 1163.2003). We thank lan Campbell, Head of the Photographic Unit of the Department of Physics, University of Oxford (Oxford, UK), for advice on photography. I.B. was sponsored in part by the Royal Society/Russian Academy of Science exchange program.

Correspondence should be addressed to Irina Bystron, University Laboratory of Physiology, University of Oxford,

Parks Road, 0xford 0X1 3PT, UK. E-mail: irina.bystron@physiol.ox.ac.uk.

DOI:10.1523/JNEUROSCI.4770-04.2005

Copyright $\odot 2005$ Society for Neuroscience $\quad$ 0270-6474/05/252781-12\$15.00/0 cellular compartment that is probably involved in guiding ingrowing axons. In various species, from rodents to primates, interstitial cells that make up the subplate are part of the preplate population, generated early in corticogenesis before the cells of the plate or concomitantly with the first plate cells (Bayer and Altman, 1990; Valverde et al., 1995). Preplate cells extend the first efferent fibers toward the IC even before formation of the cortical plate (CP) (McConnell et al., 1989; Molnár and Blakemore, 1995; Meyer et al., 1998; Soria and Fairen, 2000). These early corticofugal axons might play a part in guiding subsequent descending and ascending projections (Allendoerfer and Shatz, 1994; Molnár and Cordery, 1999). The origin of the subplate and of pioneering corticofugal axons is less clear in humans, because the subplate appears after the first neurons of the CP and continues to thicken until the 35th gestational week (Kostovic and Rakic, 1990; Meyer, 2001). The role of precocious cells remains controversial, especially in humans.

Most excitatory cortical neurons migrate radially over the glial scaffold (Rakic, 1972; deAzevedo et al., 2003), but a substantial fraction of cortical cells, mainly GABAergic, migrates tangentially from the basal telencephalon (Anderson et al., 1997; Tamamaki et al., 1997; Lavdas et al., 1999; Letinic and Rakic, 2001; Ang et al., 2003; Kriegstein and Noctor, 2004; Levitt et al., 2004). It is unclear what events trigger each mode of migration and which migratory route is taken by pioneer cells in the forebrain.

In the human embryonic brain, the future cerebral hemispheres can first be distinguished $\sim 4$ weeks after conception (Müller and O'Rahilly, 1988), but the CP does not begin to form until $\sim 3$ weeks later. In this study, we used fluorescent carbocyanine dye and early markers of neurons [microtubule-associated protein 2 (MAP2)] and axons (GAP43) to examine precocious cells and their 
Table 1. The equivalent postconceptual embryonic ages, crown-rump length, the numbers of specimens used for immunohistochemistry, for carbocynanine dye tracing, and for bisbenzimide staining alone

\begin{tabular}{|c|c|c|c|c|c|c|}
\hline \multirow[b]{2}{*}{ Carnegie stage } & \multirow{2}{*}{$\begin{array}{l}\text { Mean crown-rump } \\
\text { length }(\mathrm{mm})\end{array}$} & \multirow{2}{*}{$\begin{array}{l}\text { Approximate embryonic } \\
\text { (postconceptual) age (days) }\end{array}$} & \multirow{2}{*}{$\begin{array}{l}\text { Immunohistochemistry } \\
\text { (number) }\end{array}$} & \multicolumn{2}{|c|}{ Carbocyanine dye tracing } & \multirow{2}{*}{$\begin{array}{l}\text { Bisbenzimide staining } \\
\text { alone (number) }\end{array}$} \\
\hline & & & & Number & Dye placements & \\
\hline 14 & 6 & $33-34$ & 3 & & & 1 \\
\hline 15 & 8 & $35-36$ & 2 & & & 1 \\
\hline 16 & 9.5 & $37-39$ & 2 & 4 & $\begin{array}{l}\text { VTh/DTh, LE, hypothalamus, } \\
\text { striatocortical junction }\end{array}$ & 1 \\
\hline 17 & 12.5 & $40-41$ & 3 & 4 & VTH, DTh, ME & 1 \\
\hline 18 & 14.5 & $42-43$ & 2 & 6 & VTH, DTh, ME, cortex & 1 \\
\hline 19 & 17 & $44-46$ & 2 & 4 & DTh, cortex & 1 \\
\hline 20 & 20 & $47-49$ & 3 & 3 & DTh, cortex & 1 \\
\hline 21 & 22.5 & $50-51$ & & & & 2 \\
\hline
\end{tabular}

processes along several long-distance fiber pathways, before the appearance of the CP.

\section{Materials and Methods}

Tissue. The chronology of morphogenesis of the human embryo is described in terms of Carnegie stages (CS), defined by a number of external and internal morphological criteria (O'Rahilly and Müller, 1999). Embryos and early fetuses from CS 14-21 [embryonic days 33-51 (E33E51); days after fertilization] were obtained after legal abortions in the St. Petersburg Centre of Family Planning and Reproduction (St. Petersburg, Russia) following national guidelines in Russia, which accord with the recommendations of the Polkinghorne Report (Review of the Guidance on the Research Use of Fetuses and Fetal Material, 1989).

Histochemistry and immunohistochemistry. MAP2 occurs in developing mammalian neuronal tissue as both high- and low-molecular weight forms, with temporally regulated expression (Fujimori et al., 2002). It is much more abundant in cell bodies and dendrites than in axons. The nature of processes (whether axonal or not) was revealed with the axonal marker GAP43, which is a major membrane phosphoprotein of axonal growth cones (Skene, 1989; Dent and Meiri, 1998).

Immunohistochemistry and hematoxylin staining was performed on specimens from CS 14 to CS 20, according to standard methods (Table 1). The whole heads were fixed in 4\% PBS for between 7 and $24 \mathrm{~h}$, depending on age. The head was then embedded in paraffin and cut in a series of $7-\mu \mathrm{m}$-thick sections, in a coronal or parasagittal plane. We used mouse monoclonal antibodies (Sigma, St. Louis, MO) that recognize MAP2a, MAP2b, and MAP2c variants (1:500) and rabbit polyclonal antibodies to GAP43 (1:800) (Abcam, Cambridge, UK). Immunoreaction was revealed by the avidin-biotin-peroxidase method, using $3,3^{\prime}$ diaminobenzidine (Sigma) as chromogen. The sections were counterstained lightly with cresyl violet or fast blue and viewed with a light microscope (Leica DMRB; Leica, Nussloch, Germany). Controls were processed without the primary antibodies.

Dye tracing experiments. The fluorescent carbocyanine dye 1,1'dioctadecyl 3,3,3',3'-tetramethylindocarbocyanine perchlorate (DiI) was used to label neuronal processes and to trace the formation of early thalamofugal and corticofugal axonal projections.

Single crystals (diameter, 0.1-0.2 mm) of DiI (Molecular Probes, Eugene, OR) were inserted into parts of the telencephalon or diencephalon of fixed brains under a binocular dissecting microscope. After crystal insertion, the brains were stored at room temperature in PBS containing $0.05 \% \mathrm{Na}$ azide to prevent contamination. They were incubated for periods ranging from 3 to 4 weeks, depending on age, to allow diffusion of the dye. At the end of the incubation period, the brains were embedded in $5 \%$ agar (Sigma), and 70 - to $100-\mu$ m-thick coronal sections were cut on a vibraslicer (Leica). All sections were counterstained with bisbenzimide (10 min in $2.5 \mu \mathrm{g} / \mathrm{ml}$ solution in PBS; Sigma), mounted on slides in $\mathrm{PBS} /$ glycerol, and examined in a conventional fluorescent microscope (Leica DMRB).

Results were documented with a Nikon (Tokyo, Japan) DXM 1200 digital camera or photographed on Kodak (Rochester, NY) Ektachrome
400ASA color slide film, and figures were produced using Adobe Photoshop 7 (Adobe Systems, San Jose, CA).

\section{Results}

Various terminologies have been used to describe the lamination of the developing human forebrain. The telencephalic wall is composed initially entirely of the ventricular zone (VZ), containing neuroepithelial germinal cells. Then, the primordial plexiform layer appears, consisting of early postmigratory neurons and subpial neuropil (Marin-Padilla, 1983; Meyer and GonzalesHernadez, 1993; Zecevic et al., 1999). Some authors use the term early marginal zone for this layer (Rickmann et al., 1977; Larroche, 1981; Meyer et al., 2000). In the cortical primordium, it is now frequently termed the preplate (Stewart and Pearlman, 1987; Supér et al., 1998), and we have adopted that terminology. For the basal telencephalon and diencephalon, we follow the terminology of the Boulder Committee (1970): the very thin, cell-sparse, subpial layer is termed the marginal zone, and the postmitotic cells and fibers at the interface of the $\mathrm{VZ}$ and marginal zone are called the intermediate zone, which corresponds to the mantle zone of His (Sidman and Rakic, 1982).

In the telencephalic wall, a second proliferative layer, the subventricular zone, appears shortly before the first appearance of the $\mathrm{CP}$, which thickens progressively as postmigratory cells accumulate in it. A cell-sparse layer, consisting of axonal processes and migrating neurons, develops between the subventricular zone and the CP. This is the cortical intermediate zone.

We used immunohistochemistry to examine neurons and the nature of their processes in the human forebrain. Fluorescence microscopy after implantation of DiI crystals in a variety of sites allowed us to examine both nonaxonal processes and the first axonal projections, before CP formation.

\section{General organization of the human cortex from CS 14-21 (E33-E51)}

In young embryos (CS 14-17), the preplate consists of a thin layer of tangentially oriented cells and fibers, together with the radially oriented processes of underlying VZ cells (Fig. $1 A, E$ ). In older embryos (CS 18-20), the preplate is thicker, with cells located at variable distances from the pial surface (Fig. $1 B, C, F, G$ ). From CS 19, the subventricular zone is detectable, and at CS 21, the CP first begins to appear in the most lateral area of the telencephalic wall. It splits the preplate, leaving the marginal zone (future layer 1) above and thin intermediate zone below (Fig. $1 D)$. The prospective subplate population is visible underneath the $\mathrm{CP}$ in the most differentiated ventrolateral cortex by the end 

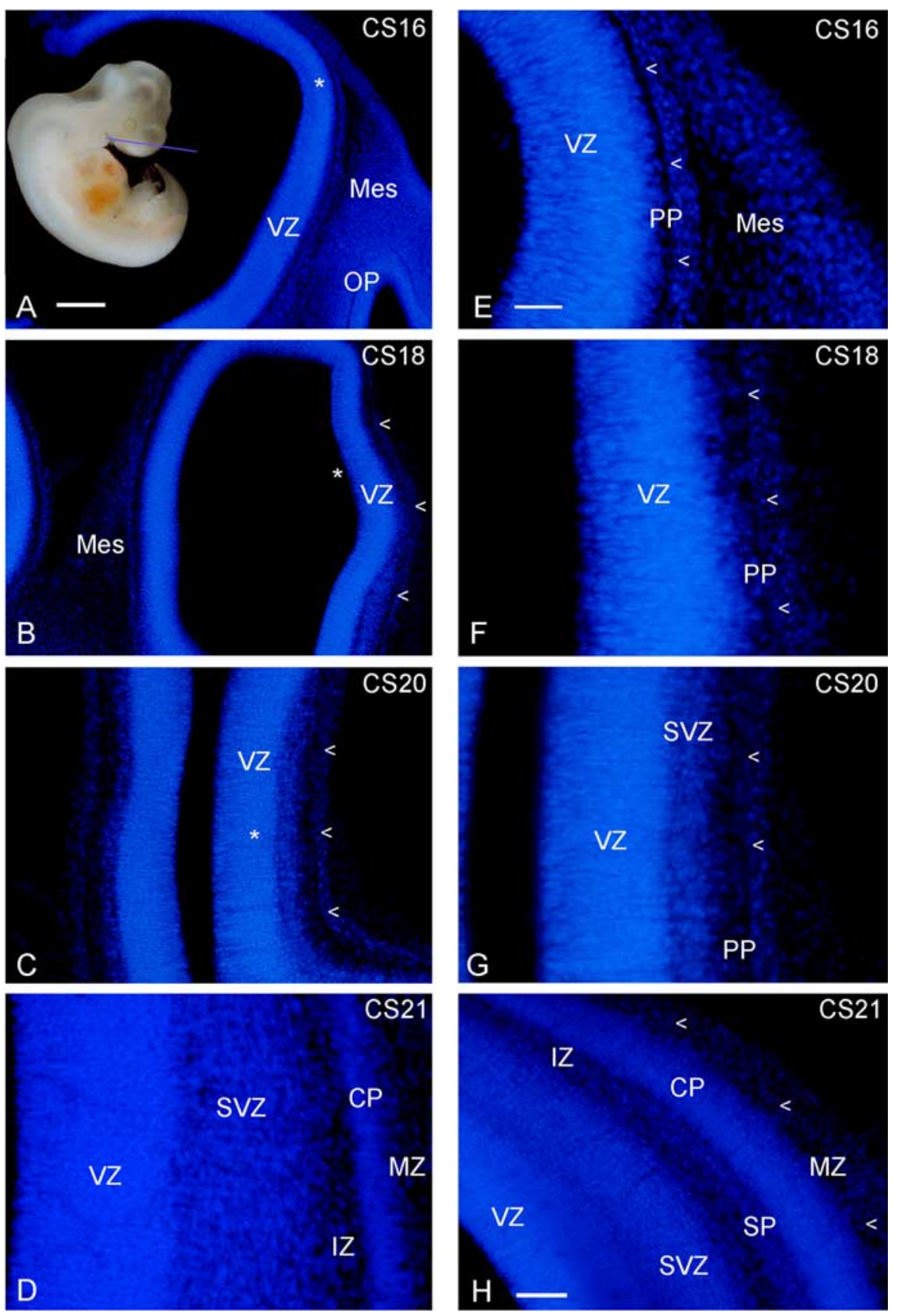

Figure 1. The early formation of cell layers in the embryonic human cerebral wall revealed by bisbenzimide counterstaining in coronal sections. The VZ is seen, adjacent to the ventricle, in all sections. $A-C$, Low-power views of the cerebral wall at $C S 16,18$, and 20 . Arrowheads demarcate the pial surface. $\boldsymbol{E}, \boldsymbol{G}$, High-power views of regions indicated by asterisks in $\boldsymbol{A}-\boldsymbol{C}$. The inset in $\boldsymbol{A}$ is a low-power view of a CS 16 embryo, showing the plane of section (blue line) used for all coronal sections in this study. At CS 16 (E), a thin layer of early postmitotic cells has occupied the cell-sparse layer beneath the pial surface to form the preplate (PP). Preplate cells are more clearly visible at $C S 18(\boldsymbol{F})$, and the preplate has thickened further by $\operatorname{CS} 20(\boldsymbol{G})$. At this stage, the subventricular zone (SVZ) has appeared as a distinct layer. $\boldsymbol{D}, \boldsymbol{H}$, Coronal sections from two specimens at CS 21. D, Early in CS 21, the true CP is now beginning to form in the most lateral areas of the telencephalic wall. The emerging (P splits the preplate into the marginal zone (MZ) above and the thin intermediate zone (IZ) below. $\boldsymbol{H}$, In this late CS 21 embryo, the CP is thicker, and cells of the prospective subplate (SP) are clearly visible underneath the $\mathrm{CP}$ in the most differentiated ventrolateral cortex. OP, Olfactory placode; Mes, mesenchyma. Scale bars: (in $\boldsymbol{A}) \boldsymbol{A}-\boldsymbol{C}, 200 \mu \mathrm{m}$; (in $\boldsymbol{E}) \boldsymbol{E}-\boldsymbol{G}, \boldsymbol{D}, 50 \mu \mathrm{m} ; \boldsymbol{H}, 100 \mu \mathrm{m}$.

of CS 21 (Fig. 1H). There is no CP in dorsolateral regions of the telencephalic wall at this stage.

Early generated neurons in the developing human forebrain: CS 14-15 (E33-E36)

In young embryos (CS 14-15), caudal regions of the CNS showed strong immunoreactivity for GAP43 and MAP2. Intense staining
CS18

was observed in the spinal cord, brainstem, cerebellum, and mesencephalon, as well as cranial and spinal nerves.

In the intermediate zone of the developing diencephalon and basal telencephalon, MAP2- and GAP43-immunopositive cells and fibers were seen running parallel to the pial surface. The network of MAP2positive cells and processes constituted the first component of the neuropil along the entire axis of mesencephalic and diencephalic prosomers (Fig. 2A). MAP2positive fibers were more abundant in the ventrolateral part of the forebrain; fewer fibers were found dorsally. A few MAP2positive cells, with an elongated soma and a horizontal process running parallel to the pial surface, were detected in the primordial cortical preplate at this early developmental stage (Fig. 2B). Some were clearly bipolar, with two coaxial processes, which is the classical appearance of early migrating cells. At CS 14, no radially oriented MAP2-positive cells were found in the VZ of the dorsal telencephalon. This implies that the precocious elongated neurons seen in the preplate at this stage are not derived from the local VZ. Indeed, the orientation of their processes and the gradient of their distribution, decreasing in number from basal to dorsal telencephalon, suggests that they might be migrating into the preplate from a location outside the cortical primordium.

At this early stage, it was technically impossible to produce carbocyanine dye placements sufficiently discrete to provide useful data on axonal projections.

Initial stages in formation of thalamofugal connectivity:

CS 16-17 (E37-E41)

Labeling for GAP43 and MAP2 showed similar distributions in caudal regions of the brain. However, the patterns of immunoreactivity were quite different in dorsal regions of the diencephalon and telencephalon (Figs. $3 A, B, 4 A, D)$. Strongly GAP43-immunoreactive axonal projections were detected in the caudal thalamus, subthalamus, and the primordium of the epithalamus (Fig. 3B). Expression of GAP43 in the rostral diencephalon was less extensive (Fig. 2E).

The distribution and intensity of GAP43 immunoreactivity reflected the degree of maturation of the postmitotic neurons and their processes. In the rostral thalamus, as shown in Figure $3, C$ and $D$, the reaction product in cell bodies with descending axons (Fig. $3 C$ ) was sparser than in large-caliber (presumably ascending) axons in the same region (Fig. 3D). The intermediate zone in the ventral thalamus (VTh) was wider and contained more GAP43-positive fibers and cells than in the dorsal thalamus (DTh) (Fig. 2E). Different patterns of GAP and MAP im- 
munoreactivity were seen in the rostral thalamus, where GAP43-positive cells and fibers were more abundant: only a few MAP2immunopositive cells were detected in the DTh at CS 17. The more mature intermediate zone of the VTh was composed partly of MAP2-positive cells and fibers.

In the rostral basal telencephalon, patterns of GAP43 and MAP2 immunoreactivity were generally quite similar (Fig. $3 E, F$ ). However, in the medial eminence, there were several groups of fibers strongly immunoreactive for GAP43 beneath the VZ.

In the intermediate zone of the basal telencephalon, scattered between the cells with round or oval somata, was a denser population of GAP43- and MAP2-stained cells with long leading and/or trailing processes. Some bipolar cells had their cell bodies and processes extending radially: these might represent postmitotic neurons migrating from the VZ of the basal telencephalon to the pial surface. However, many had tangentially oriented somata and long, tangential processes, suggesting that they might be migrating orthogonal to the radial glia (Fig. $3 G, H$ ). These cells lay in a dense plexus of GAP43-positive axons and MAP2-positive processes, whose cells of origin could often not be identified.

Immunoreactivity to GAP43 was restricted mainly to axons, but some immature cell bodies in the diencephalon and basal telencephalon were GAP43 positive (Fig. 3C,H), confirming that cells in these compartments send early axonal projections. We did not detect GAP43-positive cells in the dorsal telencephalon at CS 17 (Fig. 4D). Only small-caliber axons and some weakly expressing cells were seen in the ventrolateral preplate (Fig. $4 E, F$ ).

Monopolar and bipolar MAP2-positive cells with tangentially directed processes were widely distributed in the intermediate zone, from the basal telencephalon through the ventricular angle to the dorsomedial preplate. They decreased in density along the ventral-to-dorsal axis (Fig. 4A). MAP2positive descending processes were visible on many of these cells, and some also had ascending neurites (Fig. 4B,C). This all implies that these cells are migrating tangentially through the basal telencephalon to more dorsal regions.

Some MAP2-positive cells with bipolar morphology were also found in the VZ (Fig. 2C). Their processes extend approximately radially, and they might be migrating out of the $\mathrm{VZ}$ or into it, as described by Nadarajah and Parnavelas (2002) in the mouse. We did not detect MAP2-positive cells in the VZ of the diencephalon, and very few cells were seen in the basal telencephalon.

\section{Tracing from the diencephalon}

Crystal placement in the VTh/DTh at CS 16-17 revealed processes and back-labeled cells in the DTh, the subthalamus, and

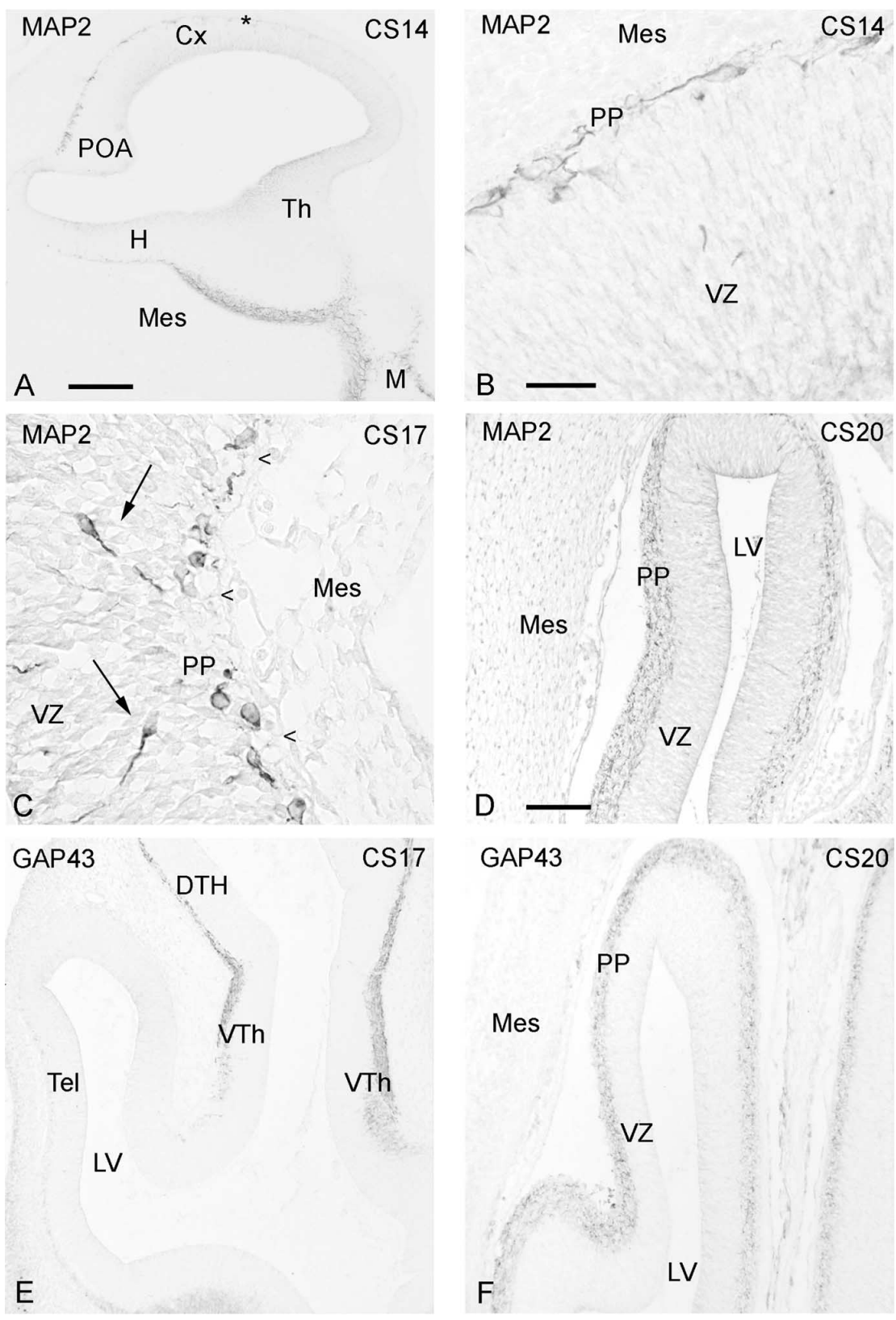

Figure 2. Patterns of MAP2 and GAP43 immunoreactivity in the human embryonic forebrain at CS 14, 17, and 20. A-D, Immunohistochemistry for the neuronal marker MAP2 revealed early postmitotic cells and their tangentially oriented processes in the mesencephalon (M), diencephalon, and telencephalon. $\boldsymbol{A}$, Sagittal section at CS 14. $\boldsymbol{B}$, High-power view of the area indicated by an asterisk in $\boldsymbol{A}$, with MAP2-positive cells and processes below the pial surface. $\boldsymbol{C}$, In this coronal section at CS 17, some approximately radially oriented MAP2-positive cells (arrows) are seen in the VZ of the cortical primordium. Arrowheads demarcate the pial surface. At CS 20, both MAP2 (D) and GAP43 $(\boldsymbol{F})$ immunoreactivity is seen in the preplate of the lateral and medial parts of the cerebral wall (coronal sections). $\boldsymbol{E}$, Low-power view of the rostral thalamus and dorsal telencephalon (Tel) at CS 17 (coronal section), showing GAP43-immunoreactive axons and cell bodies. Mes, Mesenchyma; PP, preplate; $(x$, primordium of the cortex; $H$, hypothalamus; POA, preoptic area; LV, lateral ventricle. Scale bars: (in $\boldsymbol{A}) \boldsymbol{A}, \boldsymbol{E}, \boldsymbol{F}, 200 \mu \mathrm{m}$; (in $\boldsymbol{B}) \boldsymbol{B}, \boldsymbol{C}, 25 \mu \mathrm{m} ; \boldsymbol{D}, 100 \mu \mathrm{m}$. the hypothalamus (Fig. 5A,D). There was a heavily labeled tract of (presumably thalamofugal) axons running in the intermediate zone of the ventral diencephalon (Fig. 5A), some with growth cones at their tips. A few labeled cell bodies, assumed to be the primordium of the thalamic reticular nucleus, were seen in the VTh. In addition, a distinct group of strongly labeled cells (i.e., with processes connected to the thalamus) was seen in the intermediate zone of the basal telencephalon and rostral subthalamic area, in a region considered to be the primordium of the PRN (Fig. $5 B, E$ ). Most of these cells had round or oval cell bodies, and 

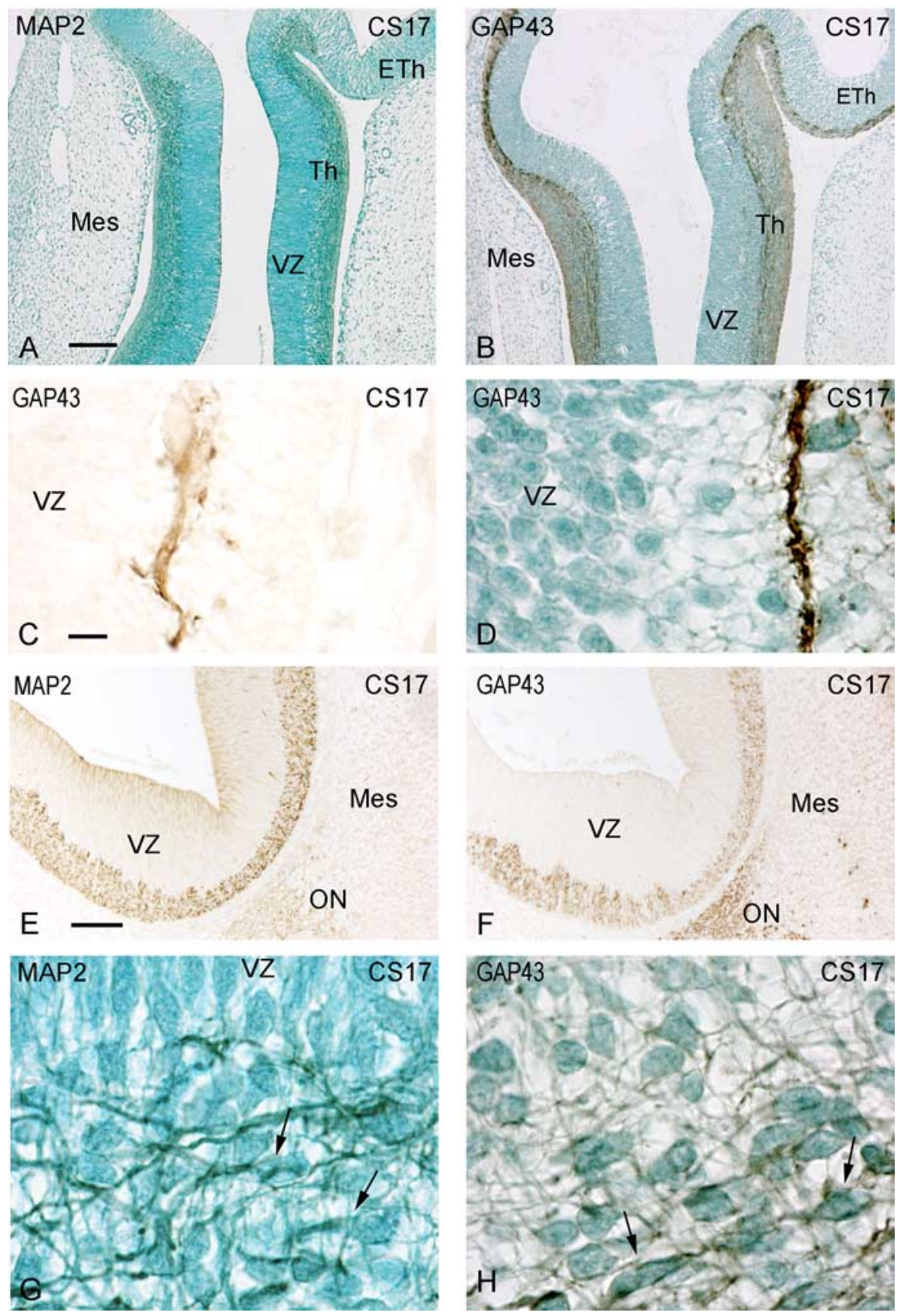

Figure 3. Comparison of MAP2 and GAP43 immunoreactivity in coronal sections through the caudal thalamus $(\boldsymbol{A}-\boldsymbol{D})$ and basal telencephalon $(\boldsymbol{E}-\boldsymbol{H})$ at $C \mathrm{~S} 17$ is shown. $\boldsymbol{A}, \boldsymbol{B}, \boldsymbol{D}, \boldsymbol{G}$, and $\boldsymbol{H}$ are counterstained with fast blue. $\boldsymbol{A}, \boldsymbol{B}$, Low-power views show the VZ of the thalamus prominently stained with fast blue. MAP2 and GAP43 immunohistochemistry revealed tangentially oriented cell bodies and processes running parallel to the pial surface in the intermediate zones of the dorsal and ventral thalamus, and axons are also seen in the epithalamus (ETh). C, D, Higher-power views of GAP43-labeled axons in the dorsal thalamus. The intensity of the immunoreactivity probably reflects the degree of maturation of the postmitotic neurons and their processes. The reaction product in some cell bodies with finer descending axons is less dense than in larger-caliber (perhaps ascending) axons (compare $\boldsymbol{C}, \boldsymbol{D}) . \boldsymbol{E}, \boldsymbol{F}$, Sections through the rostral basal telencephalon. Note the immunoreactive fibers of the olfactory nerve (ON) running through mesenchyma (Mes) from the olfactory placode, forming a network along the ventral surface of the cerebral wall in the area of the presumptive olfactory bulb. $\mathbf{G}, \boldsymbol{H}$, In the intermediate zone of the basal telencephalon, MAP2- and GAP43-stained cells with morphology suggestive of tangential migration (arrows) are sparsely distributed between round or oval cells. Scale bars: (in A) $\boldsymbol{A}, \boldsymbol{B}, 200 \mu \mathrm{m}$; (in $\boldsymbol{C}) \boldsymbol{C}, \boldsymbol{D}, \boldsymbol{G}, \boldsymbol{H}, 10 \mu \mathrm{m}$; (in $\boldsymbol{E}) \boldsymbol{E}, \boldsymbol{F}, 100 \mu \mathrm{m}$.

some of them extended a process radially into the adjacent VZ. Sparse fibers and a few retrogradely labeled cells were detected even in the rostral sections of the telencephalon, where a slight swelling represents the lateral ventricular eminence (Fig. 5C,F).

After the crystal placement in the caudal hypothalamus, only a few back-labeled cells were found in the VTh and subthalamus. This suggests that the tract of DiI-labeled fibers in the ventral diencephalon partly originates from hypothalamic cells projecting to the thalamus.

Implantation of DiI in the rostral part of the VTh/DTh at CS 17 revealed a chain of cells running through the basal telencephalon, presumed to be part of the PRN. Labeled fibers were detected in the basal telencephalon even in the rostral-most sections of the forebrain. Caudally, DiIpositive fibers also entered the DTh and coursed toward the subthalamus, where back-labeled cells were found, some with a radial process extending to the local VZ. Most labeled fibers in the hypothalamus could be traced to retrogradely labeled hypothalamic cells.

Tracing from the basal telencephalon

After crystal placement at CS 16-17 in the area of the corticostriatal junction or in the rostral basal telencephalon, we saw a chain of labeled processes and cells in the adjacent basal telencephalon, in the presumed PRN (Fig. 6A, B). This group of cells was very similar in position and appearance to that labeled from a crystal in the thalamus (compare Figs. 5F, 6C). Within the primordium of the olfactory bulb, some processes penetrated the cerebral wall and extended into the nasal mesenchyma. Caudally, DiI-positive neurites entered the dorsolateral cortex, but only a small number of retrogradely labeled cells were found in this area (Fig. 6B), some of them with a neuritic process extending radially into the VZ.

Within the population of putative perireticular cells that were labeled from thalamus or basal telencephalon were many labeled unipolar and bipolar cells, extending tangentially in the intermediate zone of the lateral ganglionic eminence (LE) and medial ganglionic eminence (ME), identical in appearance to the network of apparently tangentially migrating cells seen with MAP2 staining (Figs. $3 G, 5 E$ ).

The implantation of a DiI crystal into the ME at CS 17 also revealed numerous retrogradely labeled, presumed perireticular cells in the basal telencephalon (even the most rostral part), along future thalamocortical axon pathways (Fig. 6D$F)$. Some of them had a local process extending into the VZ (Fig. 6F), and some resembled the tangentially migrating morphology of the MAP2-positive cells in this area (compare Figs. $6 F, 4 C$ ). Some of these labeled cell bodies lay close to the corticostriatal junction, far from the crystal placement, so they presumably had a trailing process extending back into the ME (Fig. 6D,F). A stream of anterogradely labeled fibers with growth cones, together with a 
few back-labeled cells, were seen in the VTh. At this stage of development, we did not see labeled neurons in the DTh after crystal placement in the ME. A few labeled cells with large rounded somata were found in the rostral hypothalamus. They were more numerous caudally.

\section{The first corticofugal axonal} projections: CS 18-20 (E42-E49)

From CS 18, there was increasing GAP43 immunoreactivity in axons and cells of the dorsolateral preplate. Such cells with pioneering axons were seen at CS 19 in the dorsomedial aspect of the telencephalic vesicle. By CS 20, just before the appearance of the first cells of the CP, GAP43 immunoreactivity was present throughout the preplate, in both the medial and the lateral wall of the hemisphere (Fig. $2 F$ ). By this stage, GAP43 immunoreactivity also increased in the intermediate zone of the diencephalon and basal telencephalon. MAP2-positive cells and fibers were detected in the preplate of the cerebral wall of lateral and medial aspects of the hemisphere from stage 18 (Fig. 2D). Sparse MAP2-immunolabeled cells were seen in the VZ. At CS 19-20, the intermediate zone of the DTh was thicker and partly composed of MAP2-positive cells and fibers.

\section{Tracing from the diencephalon}

At CS 18, after DiI crystal placement in the VTh or DTh, the pattern of distribution of labeled projections was similar to that seen at CS 17, with a dense tract of labeled fibers, some with growth cones, extending tangentially through the marginal zone of the basal diencephalon (Fig. $7 B$ ). The number of labeled cells (i.e., projecting to the thalamus) in the mantle zone of the rostral hypothalamus and the ME had increased. Some fibers and retrogradely labeled cells were seen in the intermediate zone of the epithalamus.

The widespread population of labeled putative perireticular cells, first seen at CS 16 , was still evident. Only a few anterogradely labeled thalamic fibers extended through the basal telencephalon. They ran near or among groups of strongly labeled neurons with morphology similar to the perireticular cells. No cells were labeled in the ventricular or subventricular zones of the basal telencephalon.

At CS 19, projections labeled from the DTh were generally similar to those at CS 18, except for a dramatic decrease in the density of fibers descending tangentially to the subthalamus (Fig. 7, compare $B, D)$. Fibers were now seen accumulating at the level of the globus pallidus externus, but the primitive IC, which is later seen as a cellsparse spot at the diencephalo-telencephalic boundary (Fig. 7F), was not yet detectable. DiI placement in the DTh revealed a contin-
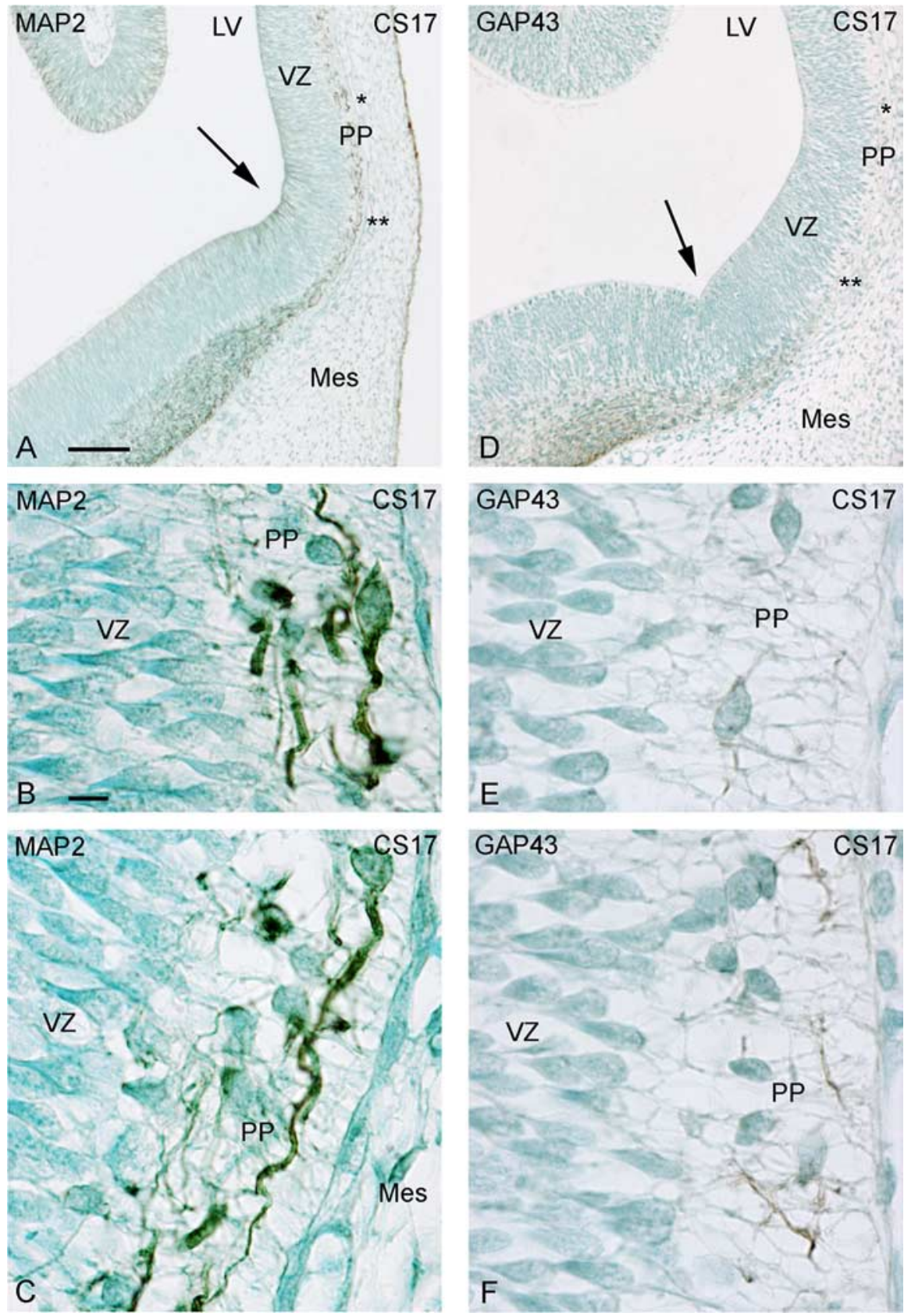

Figure 4. Comparison of MAP2 and GAP43 immunohistochemistry in the telencephalon in coronal sections at CS 17. A, D Different patterns of GAP43 and MAP2 immunoreactivity are seen in the dorsal telencephalon. The arrows mark the striatocortical boundary. $\boldsymbol{B}, \boldsymbol{C}$, High-power views of the regions indicated by single and double asterisks, respectively, in $\boldsymbol{A}$. Cells with monopolar or bipolar morphology in the preplate (PP), with long, thick, MAP2-positive neurites running parallel to the pial surface, have the features of tangentially migrating cells. $\boldsymbol{E}, \boldsymbol{F}$, High-power views of regions cells indicated by single and double asterisks, respectively, in $\boldsymbol{D}$. Some small caliber axons are GAP43 positive in the PP of ventrolateral cerebral wall $(\boldsymbol{F})$, but expression is very weak at more dorsal level (E). LV, Lateral ventricule; Mes, mesenchyma. Scale bars: (in $\boldsymbol{A}) \boldsymbol{A}, \boldsymbol{D}, 100 \mu \mathrm{m}$; (in $\boldsymbol{B}) \boldsymbol{B}, \boldsymbol{C}, \boldsymbol{E}, \boldsymbol{F}, 10 \mu \mathrm{m}$.

uous chain of cells through the primordial thalamic reticular nucleus, in the ventral diencephalon, and within the globus pallidus. Increasing numbers of perireticular cells were observed at this stage in the medial part of the ventral telencephalon (Fig. 7C). They were distributed diffusely in the intermediate zone.

Before CS 20, very few thalamic axons appear to have grown into the basal telencephalon, but at CS 20, crystal placement in the DTh stained a dense, advancing bundle of thalamocortical axons (Fig. $7 E, G$ ). The cell-sparse primitive IC, at the level of the hemispheric stalk, was now visible in sections labeled only with 

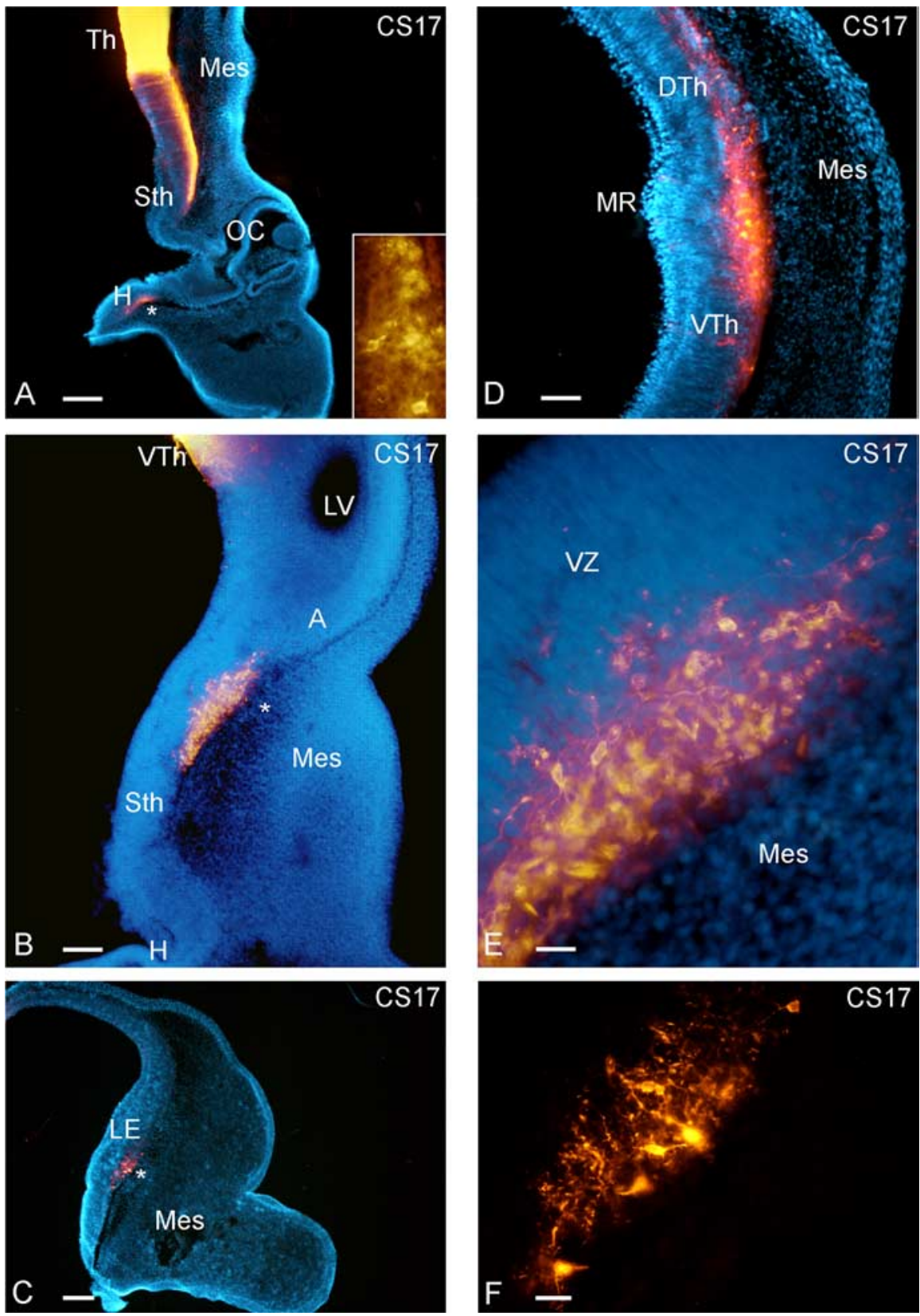

Figure 5. Carbocyanine dye tracing at CS 17 from a crystal in the border between ventral and dorsal thalamus revealed early connectivity between the dorsal thalamus, subthalamus, hypothalamus, and basal telencephalon. $A$, Coronal section through the crystal placement site. The inset figure is a magnified view of the region of the hypothalamus $(\mathrm{H})$ indicated by the asterisk in $\boldsymbol{A}$, showing labeled hypothalamic cells projecting to the thalamus. $\boldsymbol{B}, \boldsymbol{C}$, Proceeding in a rostral direction, a continuous chain of cells with fusiform morphology extends from the diencephalon to the LE. Labeled cells in the basal telencephalon, seen before the formation of the internal capsule in the human brain, resemble the perireticular neurons described in other mammalian species. $\boldsymbol{E}, \boldsymbol{F}$, High-power views of the retrogradely labeled neurons indicated by the asterisks in $\boldsymbol{B}$ and $\boldsymbol{C}$, respectively. The photomicrograph in $\boldsymbol{F}$ was taken with using a rhodamine filter. $\boldsymbol{D}$, The DTh is separated by the marginal ridge (MR) from the VTh. Mes, Mesenchyma; LV, lateral ventricule; A, amygdaloid area; Sth, subthalamus. Scale bars: $\boldsymbol{A}, \boldsymbol{C}, 200 \mu \mathrm{m} ; \boldsymbol{B}, 100 \mu \mathrm{m} ; \boldsymbol{D}, 50 \mu \mathrm{m} ; \boldsymbol{E}, \boldsymbol{F}$, $25 \mu \mathrm{m}$. OC, Optic cup.

bisbenzimide (Fig. 7F). However, fibers of the lateral forebrain bundle accumulating in this area were not tightly compacted. The brightly labeled group of thalamofugal fibers crossed the diencephalo-telencephalic boundary and ran through a large segment of the basal telencephalon. The most advanced, with growth cones at their tips, reached the LE. At this stage, cells in the basal telencephalon retrogradely labeled from the thalamus were less distinct, because they were obscured by strongly labeled thalamic fibers (Fig. $7 G$ ).
Tracing from the basal telencephalon

After crystal placement into the ME at CS 18 , we saw a dense axonal projection from the ME to the thalamus (Fig. 7A). The most advanced labeled fibers reached the DTh, some of them with large growth cones. However, no labeled cells were detected in this area. Therefore, cells of the DTh did not project to the basal telencephalon at this stage, confirming the results of thalamic crystal placement at CS 18 . In the more caudal diencephalic region, fibers labeled from the ME were less abundant, with few of them invading the thalamus. A large group of retrogradely labeled cells (i.e., extending projections to the basal telencephalon) was detected in the hypothalamus. In the VTh, they were less common, indicating that very few thalamic axons have grown to the basal telencephalon at this stage. Cells were also back-labeled in the amygdaloid area, LE, and in the ventrolateral cortex. This might be taken to indicate that the first, pioneering corticofugal axons reach the ME by CS 18 . However, evidence from cortical dye placement (see below) suggests that these early connections are not axons but merely migratory trailing processes.

Tracing from the cortex

To study the trajectories of corticofugal axonal projections and their interactions with cells of the basal telencephalon, we placed carbocyanine dye in the ventrolateral and dorsolateral cortex.

Unfortunately, it was impossible to use this approach successfully before CS 18, because removal of the pia, which is essential to avoid widespread diffusion of the dye, caused damage to the thin preplate at these early stages.

Crystal placement at CS 18-20, even high in the dorsolateral cortex, labeled an extensive network of cells and processes in the preplate. Some of the superficial, tangential processes extended down to the edge of the LE, even at CS 18 (Fig. 8A,B). However, we do not believe that most, if any, of these processes were pioneering corticofugal axons, because many of them clearly belonged to labeled cell bodies lying ventral to the crystal placement (Fig. $8 B$ ), and most of these cells were clearly bipolar with a second labeled process extending further ventrally (Fig. 8A). In some cases, such labeled bipolar cells were seen dorsal to the crystal placement, with their other process extending for a long distance further dorsally and even around the medial aspect of the hemisphere (Fig. $8 F$ ). Similar bipolar cells were also seen in the LE (Fig. $8 C, D$ ). We conclude that this superficial network of cells and processes represents the apparently migratory population seen around this time with MAP2 staining (Fig. $4 B, C$ ). 
The first clear evidence of genuine pioneering corticofugal axons was seen at CS 19. Some of the labeled processes running more deeply into the LE after crystal placement in the ventrolateral cortex had large growth cones at their tips (Fig. 8C). At CS 20 , a crystal in the lateral aspect of the cortex labeled a broad array of axons with growth cones, running deep to the pial surface into the LE (Fig. 8 E). Some labeled bipolar cells were seen lying within the array of corticofugal axons (Fig. 8G).

Neither thalamus nor ME contained any back-labeled cell bodies after cortical dye placement at this stage.

\section{Discussion}

We found a previously undescribed population of precocious neurons in the human forebrain, with extraordinarily long tangential processes. The complex network that they form, before the outgrowth of long-range axonal projections and long before the formation of the $\mathrm{CP}$, may play a role in communication between forebrain compartments. It might also play a part in the subsequent navigation of growing axons and provide a longitudinally oriented matrix for tangential migration of neurons.

So far, such a precocious network has not been described in rodents or even in nonhuman primates. Such phenotypic differences may have clinical as well as evolutionary implications.

\section{Pioneer neurons of the human cortex}

Meyer et al. (1998) showed that the earliest pioneering cells in the rat cortex are born before reelin-producing Cajal-Retzius cells, which had been thought to be the first neurons to enter the cerebral wall (Marin-Padilla, 1998; Sarnat and Flores Sarnat, 2002). In human embryos, Meyer et al. (2000) observed cortical pioneer neurons relatively late, at CS 20 (7th gestational week), almost concurrent with the first neurons of the CP. In present study, we found a population of neurons and fibers running along the entire axis of the CNS at CS 14 (in the middle of the 4 th gestational week). Two different methods (labeling with carbocyanine dye and MAP2 immunostaining) revealed a network of these cells in the preplate, with

long, bipolar processes, close to the pial surface. They appear to be the earliest neuronal population in the human telencephalon, preceding CP formation by nearly 3 weeks. At this early stage, Zecevic et al. (1999) described tangential fibers labeled for neurofilament protein in the caudal portion of the neural tube and mesencephalon, but they did not detect such fibers in the cerebral vesicles until the 6th to 7 th week of gestation.

The monopolar or bipolar morphology of pioneering cortical
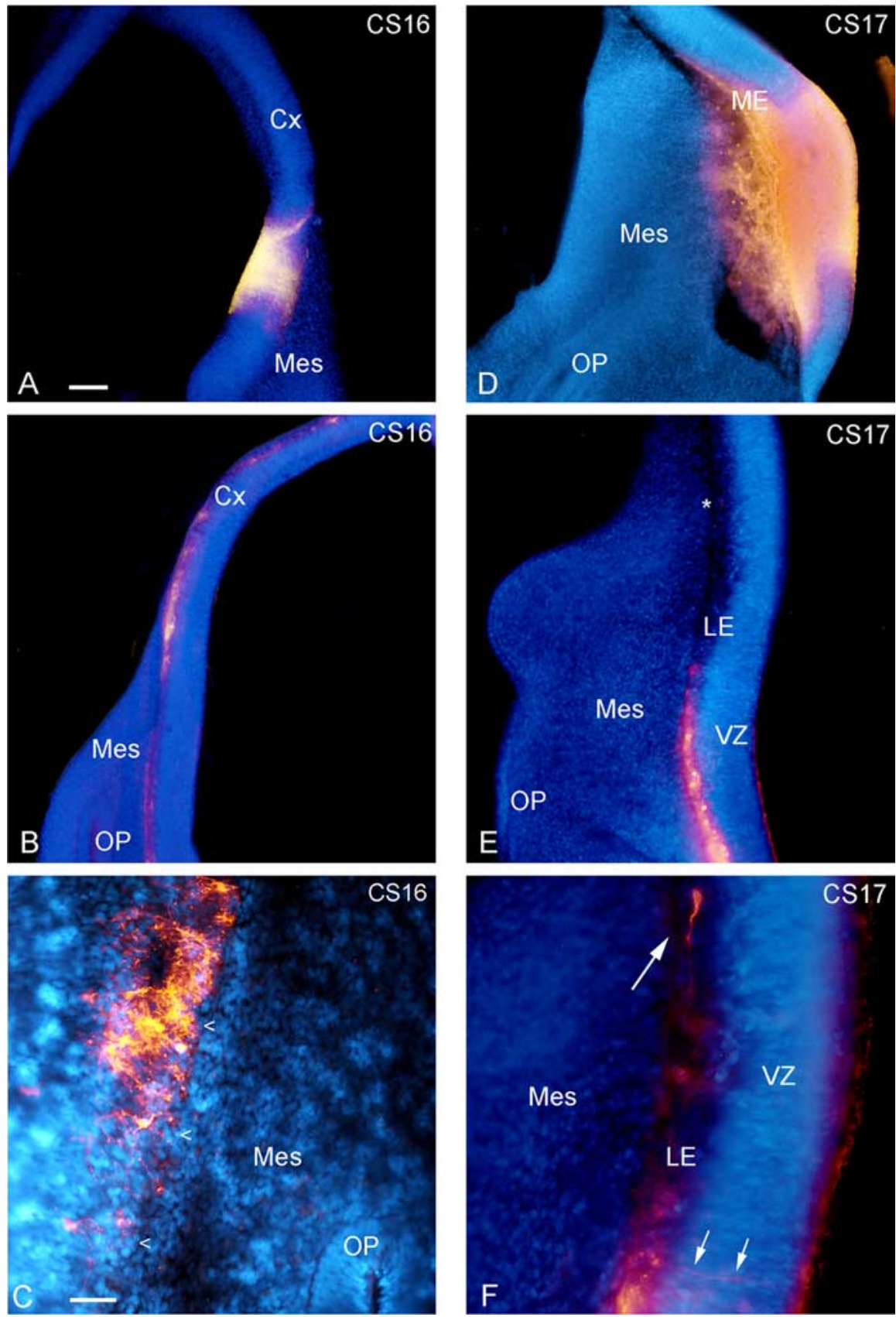

Figure 6. Patterns of labeling of cells and processes in coronal sections of the telencephalon after Dil injection in the rostral basal forebrain $(\boldsymbol{A}-\boldsymbol{C})$ at $\mathrm{CS} 16$ and in the medial ganglionic eminence $(\boldsymbol{D}-\boldsymbol{F})$ at $C S$ 17. $\boldsymbol{A}$, Section through the crystal placement site at the primordial striatocortical junction. $\boldsymbol{B}$, Labeled cells and processes in the basal and dorsal telencephalon at a more caudal level. $\boldsymbol{C}$, A section caudal to $\boldsymbol{B}$ shows numerous cells and fibers back-labeled in the intermediate zone of the basal telencephalon. Arrowheads demarcate the border between nervous and mesenchymal tissue. $\boldsymbol{D}$, Section through the crystal placement site. $\boldsymbol{E}, \boldsymbol{F}$, Pattern of distribution of retrogradely labeled neurons in the LE. $\boldsymbol{F}$, High-power view of the region indicated by the asterisk in $\boldsymbol{E}$. The morphology of the cell with a large elongated soma, indicated by an arrow, resembles that of the presumed tangentially migrating MAP2-positive cells (compare Fig. 4C). Note the labeled processes extending radially into the ventricular zone (2 downward arrows). Cx, Primordium of the cortex; Mes, mesenchyma; $O P$, olfactory placode. Scale bars: (in $A) A, B, D, E, 100 \mu \mathrm{m}$; (in $C) C, F, 50 \mu \mathrm{m}$.

MAP2-positive neurons is typical of tangentially migrating cells (Tamamaki et al., 1997; Fujimori et al., 2002). The fact that we found similar cells at the level of the ventricular angle and in the intermediate zone of the basal telencephalon (Fig. 4A,C) suggests that the pioneer neurons of the human preplate are born outside the cortical primordium, in the ventral telencephalon or elsewhere. Direct observation of cell migration in tissue culture would help to confirm this hypothesis. 

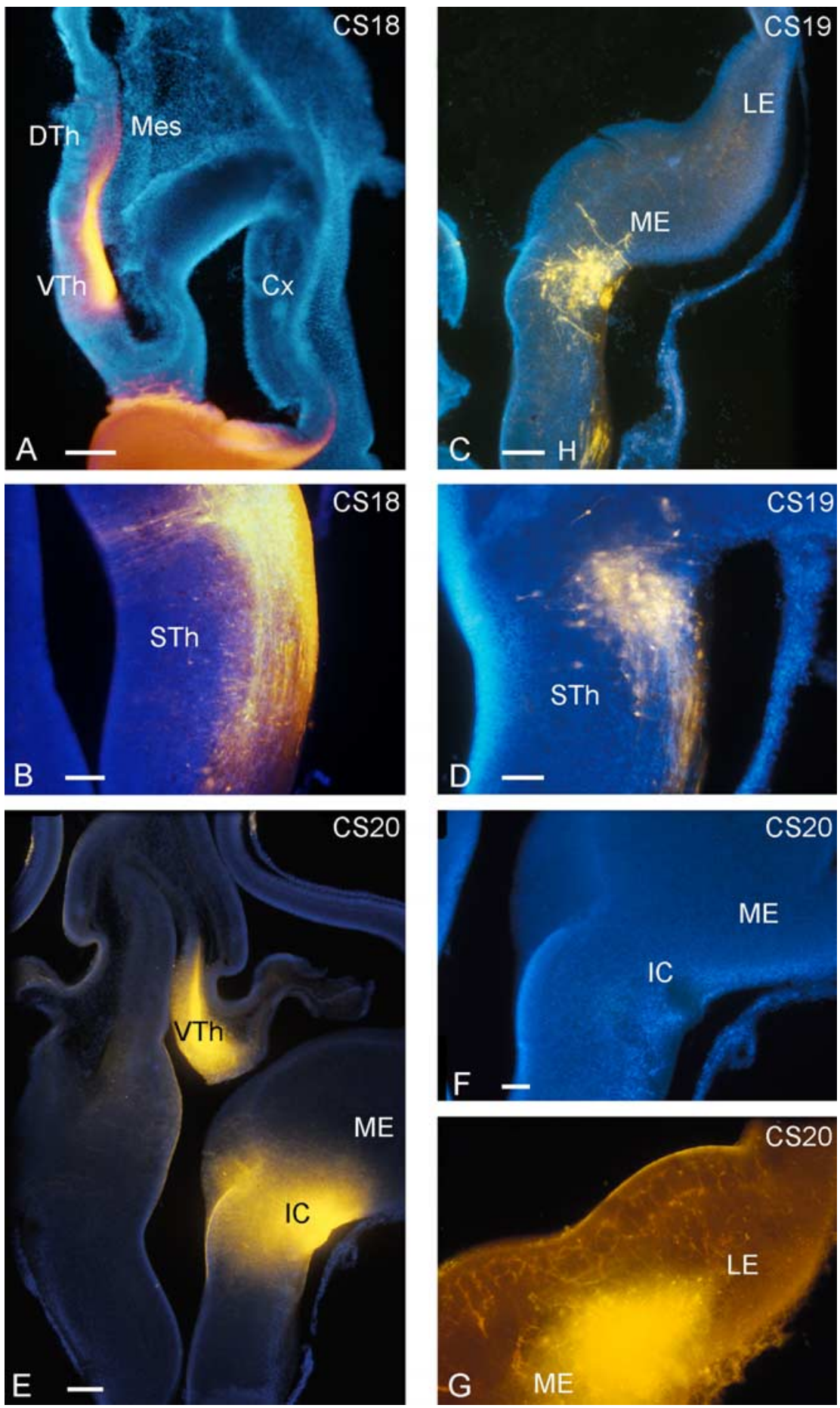

Figure 7. Thalamopetal and thalamofugal projections revealed by Dil implantation in the medial ganglionic eminence $(\boldsymbol{A})$ at CS 18 and in the dorsal thalamus $(\boldsymbol{B}-\boldsymbol{G})$ at $C S 18-20$. All sections are coronal, and all except $\mathbf{G}$ show bisbenzimide counterstaining. $A$, A section through the crystal placement site is shown. A tract of densely labeled axons is seen in the ventral and dorsal thalamus. No retrogradely labeled cells are detected in the DTh at this stage. $\boldsymbol{B}, \boldsymbol{D}$, Labeled cells in the subthalamus (STh); the density of labeled axons decreased in density between CS 18 and 19. C, Numerous cells in the intermediate zone of the ME are labeled retrogradely from the DTh. $E, G$, Labeled thalamocortical axons run through the VTh, cross the boundary between diencephalon and telencephalon through the primitive $I C$, and run through a large domain of the basal telencephalon, into the LE. $F$, The cell-free primitive $\mathrm{IC}$ is seen clearly at the level of the hemispheric stalk in this nonfluorescently illuminated view. $C x$, Primordium of the cortex; H, hypothalamus; Mes, mesenchyma; Scale bars: (in $A, B, D, F) A, B, D, F, G, 100 \mu \mathrm{m} ; C, E, 200 \mu \mathrm{m}$.

A continuum of doublecortin-positive, tangentially oriented cells and fibers has been described previously in the human preplate and ganglionic eminence at the middle of the 5 th gestational week, but the cells of origin of the fiber plexus were not deter- mined (Meyer et al., 2002). Those authors suggested that these horizontal fibers may be analogous to the long leading processes extended by migrating basilar pontine neurons in the mouse brain (Yee et al., 1999). Our data directly confirmed the extraordinary length of the earliest neuronal processes in the human telencephalon.

Rakic and Zecevic (2003), using in situ hybridization and antibodies to transcription factors DLX and NKX.1 and to neuronal markers, concluded that some cortical interneurons, originating from the ganglionic eminence, reach the preplate layer by tangential migration at CS 19-20 (6th to 7 th gestational week). However, they proposed that the first neurons derive from the cortical VZ. Our data suggest that the first neurons in the human preplate, from at least CS 14, originate subcortically. Morante Oria et al. (2003) have recently demonstrated the subpallial origin of pioneer neurons in mice by green fluorescent protein transfection and labeling with membrane-permeant dyes in cultured forebrain slices. They also described a network of pioneer cells extending from the thalamic and ganglionic eminences to the cortex.

Rakic (1990) proposed that radially migrating postmitotic cells follow radial glia, whereas tangential migration follows preexisting axonal pathways, as demonstrated elsewhere in the brain (Yoshida et al., 1995; Phelps et al., 1996; Golden et al., 1997; Ortino et al., 2003). However, pioneer neurons with morphology typical of tangential migration are seen in cortical primordium at CS 14, well before the first corticofugal and corticopetal axonal projections (see below). Such early migration must be independent of axonal guidance. Early in corticogenesis, nuclear translocation along a leading process, independent of glial or axonal support, is the prevalent mode of radial migration (Nadarajah et al., 2001; Nadarajah and Parnavelas, 2002). The pioneer neurons that we have seen have the appearance of cells undergoing somal migration in other parts of the CNS (Morest 1970; Rakic, 1971; Rivas and Hatten, 1995), and we suggest that they use this mechanism to enter the preplate. Our data imply that the first processes reaching the preplate originate in the basal telencephalon.

\section{The first corticofugal and corticopetal projections}

As a postmitotic cell begins to express neuronal markers it changes its morphology, extending processes to become a migrating cell and later a differentiated neuron. The axon and dendrites can derive from the early processes, but the pattern of 
transformation is variable. In rat inferior olive (Bourrat and Sotelo, 1988) and chick medulla (Book et al., 1991), axons derive from the leading processes of migrating cells. However, Yee et al. (1999) found none of the generic markers for axons in the leading processes of migrating basilar pontine neurons in the mouse, and neurons in vitro can generate axons from either pole (Hayashi et al., 2002). Hatanaka and Murakami (2002) suggested that the trailing processes of radially migrating cortical pyramidal cells give rise to axons and their leading neurites transform into apical dendrites.

Because pioneer cells of the rat preplate are said to send transient axonal projections into the nascent IC (Soria and Fairen, 2000), we expected that the descending processes of early MAP2-positive cells in the human preplate would become axonal. The axonal marker GAP43 is first detected in the preplate of the ventrolateral cortex at CS 17 (Fig. 4D-F). However, it is found in thin processes, different in appearance from the thick MAP2-positive processes of pioneer cells seen at the same stage (compare Fig. $4 B, C$ and $E, F$ ). Carbocyanine dye staining of the dorsal cortex at CS 18 reveals elongated cells in the preplate with long tangential processes (Fig. 8A,B), but it is unlikely that most of these are true axons.

The nature and developmental role of the first afferent axons to the human cortex remain to be defined. It has been suggested that monoaminergic axons from nuclei of the brainstem reticular activating system are the first to arrive (MarinPadilla, 1992). The first catecholaminergetic axons enter the anlage of the cerebral cortex at the 7 th gestational week, around the time of the appearance of the CP (Zecevic and Verney 1995; Verney, 1999). We have shown that the first thalamocortical axons enter the cerebral wall at about the same age (Bystron et al., 2003).

By CS 18, some neurons at the corticostriatal junction have processes that extend to the dorsolateral cortex (Fig. $8 A, B$ ). They share the same growth compartment as tangential fibers, lying directly above the VZ. At least some of these processes appear to be early corticopetal and corticofugal axons, because they have large growth cones at their tips, and GAP43 immunoreactivity appears in the ventrolateral cerebral wall at about this time. In this respect, human seems similar to mouse and hamster, in which corticopetal projections from basal telencephalon arrive almost concurrently with CP neurons (Métin and Godement, 1996; Auladell et al., 2000). In the rat, they appear relatively late, after thalamic fibers have reached the cortex (Adams and Baker, 1995; Molnár and Cordery, 1999). The first clear array of corticofugal axons is seen
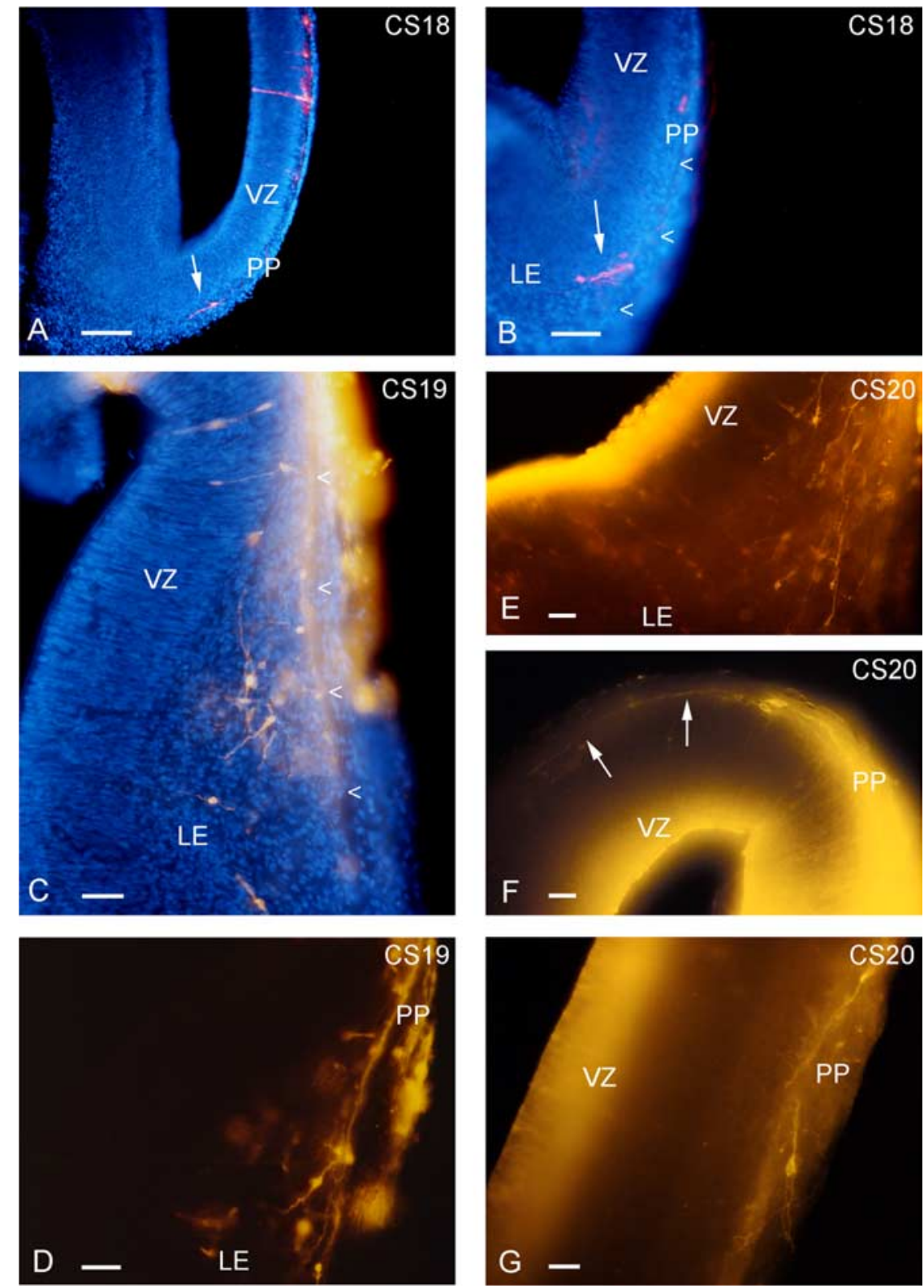

Figure 8. Placement of Dil crystals in the cortex at CS $18(\boldsymbol{A}, \boldsymbol{B}), C S 19(\boldsymbol{C}, \boldsymbol{D})$, and $C S 20(\boldsymbol{E}-\boldsymbol{G})$ revealed the network of pioneer cells and processes, as well as early axonal projections in the rostral forebrain. $A, B$, Dil in the dorsolateral cortex at CS 18 revealed a chain of tangentially elongated, bipolarcells in the preplate(PP). Arrowheads indicate the pial surface. Some of these bipolar cells (arrows in $\boldsymbol{A}$ and $\boldsymbol{B}$ ), with processes extending far up into the crystal site, were seen at the striatocortical junction. $\boldsymbol{C}, \boldsymbol{D}, A$ crystal placed in ventrolateral cortex at CS 19 labeled bipolar cells in the rostral LE, similar in morphology to those in the cortical preplate. These cells of the basal telencephalon must have processes extending up into the region of the crystal placement. Some presumed corticofugal axons, with growth cones at their tips, were also seen, extending down to the rostral basal telencephalon. $\boldsymbol{E}$, At CS 20, an array of anterogradely labeled corticofugal axons, tipped with large growth cones, is seen crossing the striatocortical boundary after crystal placement in the lateral aspect of the cortex. $F$, A few fibers and labeled bipolar cells were detected in the dorsomedial cortical wall after dorsolateral crystal placement. The medially directed processes of these cells, indicated by arrows, extended for a long distance under the medial surface of the hemisphere. G, Retrogradely labeled bipolar cells with long tangential processes were seen among the corticofugal axons ventral to the crystal placement. Scale bars: $A, 100 \mu \mathrm{m} ; \boldsymbol{B}-\boldsymbol{E}, 50 \mu \mathrm{m} ; \boldsymbol{F}, \mathbf{G}, 25 \mu \mathrm{m}$.

at CS 19-20 (Fig. 8C,E), but they run deeper and might well arise from neurons that have reached the preplate from the VZ.

\section{Early projections to the thalamus from cells along the thalamocortical pathway}

Crystal placement into the thalamus at CS 16-17 revealed a chain of cells extending from the ventral diencephalon to the intermediate zone of the basal telencephalon (Fig. 5). The telencephalic cells projecting to the thalamus showed a strong resemblance to 
the PRN described in other mammalian species (Mitrofanis and Baker, 1993; Contreras Rodriguez et al., 2002). It has been suggested that PRN cells form early connections to the thalamus and play a part in the subsequent guidance of thalamocortical fibers (Molnár and Cordery, 1999). In humans, such cells have been described much later, during fetal development (Letinic and Kostovic, 1996; Ulfig et al., 1998, 2000). However, these cells are present and already project to the thalamus at CS 16-17 (Fig. $5 B, E$ ), before the formation of the distinct fiber tract of the IC at CS 20 (Fig. 7F). They lie in both the LE and the ME, as in the rat (Molnár and Cordery, 1999).

\section{Thalamocortical projections}

At CS 18, some $10 \mathrm{~d}$ after axons of the putative thalamic reticular nucleus and PRN enter the DTh, the first thalamic axons reach the ventral telencephalon. By CS 20, they reach the LE (Fig. 7G).

In humans, as in rodents, thalamic and cortical axons appear to enter the basal telencephalon simultaneously, from opposite sides, in the same growth compartment. As in hamsters (Métin and Godement, 1996), thalamic and cortical axons cross diencephalic-telencephalic and striatocortical boundaries before the start of CP formation, whereas in mice and rats, this occurs after formation of the CP (Molnár et al., 1998; Braisted et al., 1999). Molnár and Blakemore (1995) presented evidence that thalamic axons in rodents confront and navigate over the array of preexisting corticofugal fibers (the handshake hypothesis). More work is needed to see whether such a relationship occurs in humans.

From the earliest age we studied (CS 16-17), the human DTh was also connected with cells outside the thalamocortical route. In addition to thalamo-epithalamic connections, we found a cell group in the hypothalamic region transiently projecting to the DTh. These projections began to disappear after CS 18, although some remained until CS 19 in the dorsal subthalamic area. After crystal placement in the thalamus, we saw labeled processes, some with growth cones at their tips, in the hypothalamus, a region thought to be nonpermissive for thalamic axons in rodents (Braisted et al., 1999, 2000). Some of these processes might have belonged to the migratory pioneer cells stretching between thalamus and hypothalamus, but it is possible that there is a transient thalamo-hypothalamic projection in humans.

MAP2- and GAP43-immunopositive fibers, parallel to the pial surface, are seen clearly in the intermediate zone of the diencephalon at CS $16-17$ (Fig. 3A,E). In the developing rat thalamus, vimentin immunostaining reveals transient, longitudinally oriented fibers associated with migrating neurons (Frassoni et al., 2000). However, the origin and termination of such nonradial processes in the diencephalon remain to be elucidated.

\section{References}

Adams NC, Baker GE (1995) Cells of the perireticular nucleus project to the developing neocortex of the rat. J Comp Neurol 359:613-626.

Allendoerfer KL, Shatz CJ (1994) The subplate, a transient neocortical structure: its role in the development of connections between thalamus and cortex. Annu Rev Neurosci 17:185-218.

Anderson SA, Eisenstat DD, Shi L, Rubenstein JL (1997) Interneuron migration from basal forebrain to neocortex: dependence on Dlx genes. Science 278:474-476.

Ang Jr ES, Haydar TE, Gluncic V, Rakic P (2003) Four-dimentional migratory coordinates of GABAergic interneurons in the developing mouse cortex. J Neurosci 23:5805-5815.

Auladell C, Perez Sust P, Supèr H, Soriano E (2000) The early development of thalamocortical and corticothalamic projections in the mouse. Anat Embryol (Berl) 201:169-179.

Bate CM (1976) Pioneer neurones in an insect embryo. Nature 260:54-56.
Bayer SA, Altman J (1990) Development of layer I and the subplate in the rat neocortex. Exp Neurol 107:48-62.

Book KJ, Howard R, Morest DK (1991) Direct observation in vitro of how neuroblasts migrate: medulla and cochleovestibular ganglion of the chick embryo. Exp Neurol 111:228-243.

Boulder Committee (1970) Embryonic vertebrate central nervous system: revised terminology. Anat Rec 166:257-262.

Bourrat F, Sotelo C (1988) Migratory pathways and neuritic differentiation of inferior olivary neurons in the rat embryo. Axonal tracing study using the in vitro slab technique. Brain Res 467:19-37.

Braisted JE, Tuttle R, O'Leary DD (1999) Thalamocortical axons are influenced by chemorepellent and chemoattractant activities localized to decision points along their path. Dev Biol 208:430-440.

Braisted JE, Catalano SM, Stimac R, Kennedy TE, Tessier Lavigne M, Shatz CJ, O'Leary DD (2000) Netrin-1 promotes thalamic axon growth and is required for proper development of the thalamocortical projection. J Neurosci 20:5792-5801.

Bystron I, Blakemore C, Otellin V, Molnár Z (2003) Early development of the thalamic reticular and perireticular nuclei in the human brain. J Physiol (Lond) 548P:144.

Contreras Rodriguez J, Gonzalez Soriano J, Martinez Sainz P, Rodriguez Veiga E (2002) The thalamic reticular and perireticular nuclei in developing rabbits: patterns of parvalbumin expression. Brain Res Dev Brain Res 136:123-133.

deAzevedo LC, Fallet C, Moura Neto V, Daumas Duport C, Hedin Pereira C, Lent R (2003) Cortical radial glial cells in human fetuses: depthcorrelated transformation into astrocytes. J Neurobiol 55:288-298.

Deng J, Elberger AJ (2003) Corticothalamic and thalamocortical pathfinding in the mouse: dependence on intermediate targets and guidance axis. Anat Embryol (Berl) 207:177-192.

Dent EW, Meiri KF (1998) Distribution of phosphorylated GAP-43 (neuromodulin) in growth cones directly reflects growth cone behavior. J Neurobiol 35:287-299.

Frassoni C, Amadeo A, Ortino B, Jaranowska A, Spreafico R (2000) Organization of radial and non-radial glia in the developing rat thalamus. J Comp Neurol 428:527-542.

Fujimori K, Takauji R, Tamamaki N (2002) Differential localization of high- and low-molecular-weight variants of microtubule-associated protein 2 in the developing rat telencephalon. J Comp Neurol 449:330-342.

Golden JA, Zitz JC, McFadden K, Cepko CL (1997) Cell migration in the developing chick diencephalon. Development 124:3525-3533.

Goodman CS, Shatz CJ (1993) Developmental mechanisms that generate precise patterns of neuronal connectivity. Cell [Suppl] 72:77-98.

Hatanaka Y, Murakami F (2002) In vitro analysis of the origin, migratory behavior, and maturation of cortical pyramidal cells. J Comp Neurol 454:1-14.

Hayashi K, Kawai Hirai R, Ishikawa K, Takata K (2002) Reversal of neuronal polarity characterized by conversion of dendrites into axons in neonatal rat cortical neurons in vitro. Neuroscience 110:7-17.

Knyihár E, Csillik B, Rakic P (1978) Transient synapses in the embryonic primate spinal cord. Science 202:1206-1209.

Kostovic I, Rakic P (1980) Cytology and time of origin of interstitial neurons in the white matter in infant and adult human and monkey telencephalon. J Neurocytol 9:219-242.

Kostovic I, Rakic P (1990) Developmental history of the transient subplate zone in the visual and somatosensory cortex of the macaque monkey and human brain. J Comp Neurol 297:441-470.

Kriegstein AR, Noctor SC (2004) Patterns of neuronal migration in the embryonic cortex. Trends Neurosci 27:392-399.

Larroche JC (1981) The marginal layer in the neocortex of a 7 week-old human embryo. A light and electron microscopic study. Anat Embryol (Berl) 162:301-312.

Lavdas AA, Grigoriou M, Pachnis V, Parnavelas JG (1999) The medial ganglionic eminence gives rise to a population of early neurons in the developing cerebral cortex. J Neurosci 19:7881-7888.

Letinic K, Kostovic I (1996) Transient neuronal population of the internal capsule in the developing human cerebrum. NeuroReport 7:2159-2162.

Letinic K, Rakic P (2001) Telencephalic origin of human thalamic GABAergic neurons. Nat Neurosci 4:931-936.

Levitt P, Eagleson KL, Powell EM (2004) Regulation of neocortical interneuron development and the implications for neurodevelopmental disorders. Trends Neurosci 27:400-406. 
Macdonald R, Xu Q, Barth KA, Mikkola I, Holder N, Fjose A, Krauss S, Wilson SW (1994) Regulatory gene expression boundaries demarcate sites of neuronal differentiation in the embryonic zebrafish forebrain. Neuron 13:1039-1053.

Marin-Padilla M (1983) Structural organization of the human cerebral cortex prior to the appearance of the cortical plate. Anat Embryol (Berl) 168:21-40.

Marin-Padilla M (1992) Ontogenesis of the pyramidal cell of the mammalian neocortex and developmental cytoarchitectonics: a unifying theory. J Comp Neurol 321:223-240.

Marin-Padilla M (1998) Cajal-Retzius cells and the development of the neocortex. Trends Neurosci 21:64-71.

McConnell SK, Ghosh A, Shatz CJ (1989) Subplate neurons pioneer the first axon pathway from the cerebral cortex. Science 245:978-982.

Métin C, Godement P (1996) The ganglionic eminence may be an intermediate target for corticofugal and thalamocortical axons. J Neurosci 16:3219-3235.

Meyer G (2001) Human neocortical development: the importance of embryonic and early fetal events. Neuroscientist 7:303-314.

Meyer G, Gonzalez-Hernandez T (1993) Developmental changes in layer I of the human neocortex during prenatal life: a DiI-tracing and AChE and NADPH-d histochemistry study. J Comp Neurol 338:317-336.

Meyer G, Soria JM, Martinez Galan JR, Martin Clemente B, Fairen A (1998) Different origins and developmental histories of transient neurons in the marginal zone of the fetal and neonatal rat cortex. J Comp Neurol 397:493-518.

Meyer G, Schaaps JP, Moreau L, Goffinet AM (2000) Embryonic and early fetal development of the human neocortex. J Neurosci 20:1858-1868.

Meyer G, Perez Garcia CG, Gleeson JG (2002) Selective expression of doublecortin and LIS1 in developing human cortex suggests unique modes of neuronal movement. Cereb Cortex 12:1225-1236.

Mitrofanis J, Baker GE (1993) Development of the thalamic reticular and perireticular nuclei in rats and their relationship to the course of growing corticofugal and corticopetal axons. J Comp Neurol 338:575-587.

Molnár Z, Blakemore C (1995) How do thalamic axons find their way to the cortex? Trends Neurosci 18:389-397.

Molnár Z, Cordery P (1999) Connections between cells of the internal capsule, thalamus, and cerebral cortex in embryonic rat. J Comp Neurol 413:1-25.

Molnár Z, Adams R, Blakemore C (1998) Mechanisms underlying the early establishment of thalamocortical connections in the rat. J Neurosci 18:5723-5745.

Morante Oria J, Carleton A, Ortino B, Kremer EJ, Fairen A, Lledo PM (2003) Subpallial origin of a population of projecting pioneer neurons during corticogenesis. Proc Natl Acad Sci USA 100:12468-12473.

Morest DK (1970) A study of neurogenesis in the forebrain of opossum pouch young. Z Anat Entwicklungsgesch 130:265-305.

Müller F, O'Rahilly R (1988) The first appearance of the future cerebral hemispheres in the human embryo at stage 14. Anat Embryol (Berl) 177:495-511.

Nadarajah B, Parnavelas JG (2002) Modes of neuronal migration in the developing cerebral cortex. Nat Rev Neurosci 3:423-432.

Nadarajah B, Brunstrom JE, Grutzendler J, Wong RO, Pearlman AL (2001) Two modes of radial migration in early development of the cerebral cortex. Nat Neurosci 4:143-150.

O’Rahilly R, Müller F (1999) The embryonic human brain: an atlas of developmental stages. New York: Wiley.

Ortino B, Inverardi F, Morante Oria J, Fairen A, Frassoni C (2003) Substrates and routes of migration of early generated neurons in the developing rat thalamus. Eur J Neurosci 18:323-332.
Phelps PE, Barber RP, Vaughn JE (1996) Nonradial migration of interneurons can be experimentally altered in spinal cord slice cultures. Development 122:2013-2022.

Rakic P (1971) Neuron-glia relationship during granule cell migration in developing cerebellar cortex. A Golgi and electronmicroscopic study in Macacus rhesus. J Comp Neurol 141:283-312.

Rakic P (1972) Mode of cell migration to the superficial layers of fetal monkey neocortex. J Comp Neurol 145:61-83.

Rakic P (1990) Principles of neural cell migration. Experientia 46:882-891.

Rakic S, Zecevic N (2003) Emerging complexity of layer I in human cerebral cortex. Cereb Cortex 13:1072-1083.

Rickmann M, Chronwall BM, Wolff JR (1977) On the development of nonpyramidal neurons and axons outside the cortical plate: the early marginal zone as a pallial anlage. Anat Embryol (Berl) 151:285-307.

Rivas RJ, Hatten ME (1995) Motility and cytoskeletal organization of migrating cerebellar granule neurons. J Neurosci 15:981-989.

Sarnat HB, Flores Sarnat L (2002) Cajal-Retzius and subplate neurons: their role in cortical development. Eur J Paediatr Neurol 6:91-97.

Sidman RL, Rakic P (1973) Neuronal migration, with special reference to developing human brain: a review. Brain Res 62:1-35.

Sidman RL, Rakic P (1982) Development of the human central nervous system. In: Histology and histopathology of the nervous system (Haymaker W, Adams RD, eds), pp 3-145. Springfield, IL: Thomas.

Skene JH (1989) Axonal growth-associated proteins. Annu Rev Neurosci 12:127-156.

Soria JM, Fairen A (2000) Cellular mosaics in the rat marginal zone define an early neocortical territorialization. Cereb Cortex 10:400-412.

Stewart GR, Pearlman AL (1987) Fibronectin-like immunoreactivity in the developing cerebral cortex. J Neurosci 7:3325-3333.

Supér H, Soriano E, Uylings HB (1998) The functions of the preplate in development and evolution of the neocortex and hippocampus. Brain Res Brain Res Rev 27:40-64.

Tamamaki N, Fujimori KE, Takauji R (1997) Origin and route of tangentially migrating neurons in the developing neocortical intermediate zone. J Neurosci 17:8313-8323.

Ulfig N, Nickel J, Bohl J (1998) Transient features of the thalamic reticular nucleus in the human foetal brain. Eur J Neurosci 10:3773-3784.

Ulfig N, Neudorfer F, Bohl J (2000) Transient structures of the human fetal brain: subplate, thalamic reticular complex, ganglionic eminence. Histol Histopathol 15:771-790.

Valverde F, De Carlos JA, Lopez Mascaraque L (1995) Time of origin and early fate of preplate cells in the cerebral cortex of the rat. Cereb Cortex 5:483-493.

Verney C (1999) Distribution of the catecholaminergic neurons in the central nervous system of human embryos and fetuses. Microsc Res Tech 46:24-47.

Yee KT, Simon HH, Tessier Lavigne M, O’Leary DM (1999) Extension of long leading processes and neuronal migration in the mammalian brain directed by the chemoattractant netrin-1. Neuron 24:607-622.

Yoshida K, Tobet SA, Crandall JE, Jimenez TP, Schwarting GA (1995) The migration of luteinizing hormone-releasing hormone neurons in the developing rat is associated with a transient, caudal projection of the vomeronasal nerve. J Neurosci 15:7769-7777.

Zecevic N, Verney C (1995) Development of the catecholamine neurons in human embryos and fetuses, with special emphasis on the innervation of the cerebral cortex. J Comp Neurol 351:509-535.

Zecevic N, Milosevic A, Rakic S, Marin-Padilla M (1999) Early development and composition of the human primordial plexiform layer: an immunohistochemical study. J Comp Neurol 412:241-254. 